\title{
The Extent of Parents' Acceptance with Regard to Usage of General Anaesthesia for Their Children during Dental Procedure in Riyadh City
}

\author{
Haneen Alshukairy ${ }^{1}$, Bayan Alsahwan², Massoma Alkhabbaz ${ }^{3}$, \\ Maryam Alkhwajah ${ }^{4}$, Zainab Bumajdad ${ }^{5}$, Zahra Alradwan ${ }^{6}$ \\ ${ }^{1}$ Department of Preventive Dentistry, College of Dentistry, Riyadh Elm University, Riyadh, Saudi Arabia. \\ 2, 3, 4, 5, 6 College of Dentistry, Riyadh Elm University, Riyadh, Saudi Arabia.
}

\section{ABSTRACT}

\section{BACKGROUND}

Investigators have begun to assess the parental acceptance on General Anaesthesia (GA) in pediatric dentistry. Patient satisfaction and knowledge has an essential role in determining the utilization of the healthcare services. Physiologic and functional outcomes can affect completion of the treatment process that is one of the Factors that influence parental decision for seeking care.

\section{METHODS}

In this survey, a structured self-administered and close ended questionnaire, was used to assess parents' acceptance for dental treatments under general anaesthesia for their child. Parents whose children were going to undergo dental treatments in Riyadh Elm University, were approached with this questionnaire. All parents fulfilling inclusion criteria were explained about the purpose of the study and a total of 452 parents provided informed consent during the aforementioned period was included in the survey.

\section{RESULTS}

A total of 452 parents of the children participated in the study. The educational level of the parents was found to be significantly associated with the effectiveness of the comprehensive dental care for their child under GA. Child age showed significant association with the parental refusal of dental treatment under GA. Educational level of the parents and residence were found to be significantly associated with the perception that the dental treatment under GA is indicated for a specific class of patients. $(\mathrm{P}<0.05)$

\section{CONCLUSIONS}

Education level of parent's have important role in knowlage and awareness to treat their children under GA. Regular dental check up is important. Educating parents about oral health and diseases is important to increase the awareness about prevention rather than intervention.

\section{KEY WORDS}

Dentistry, General Anaesthesia, Paediatric Dentistry, Parent Acceptance
Corresponding Author: Dr. Masooma Alkhabbaz. Dental Interns, College of Dentistry, Riyadh Elm University, Riyadh, Saudi Arabia. E-mail: massoma.j.alkhabbaz@gmail.com

DOI: $10.14260 /$ jemds/2020/723

How to Cite This Article:

Alshukairy $H$, Alsahwan B, Alkhabbaz $M$, et al. The extent of parents' acceptance with regard to usage of general anaesthesia for their children during dental procedure in Riyadh city. J Evolution Med Dent Sci 2020;9(44):3289-3293, $10.14260 /$ jemds/2020/723

Submission 27-07-2020,

Peer Review 22-09-2020,

Acceptance 28-09-2020,

Published 02-11-2020.

Copyright (C) 2020 Haneen Alshukairy et al. This is an open access article distributed under Creative Commons Attribution License [Attribution 4.0 International (CC $B Y 4.0)]$ 


\section{BACKGROUND}

Good oral health and dentition are important for speaking, effective masticating, and of course from beauty point of view for smiling. Most children can undergo in-office regular dental treatments. ${ }^{1}$ Behavioral management techniques are one of the techniques that have been used for uncooperative children who refuse Dental treatment due to fear and anxiety. ${ }^{2,3}$

However, some children cannot be managed in their conscious state by these methods and subsequently they require other methods. ${ }^{2,4}$ For those children, treatments under GA have many advantages, which include the provision of treatments that are safe, efficient, and convenient. Extensive high-quality treatment is performed in a single visit, with minimal discomfort to the patient; less physical and mental stress for both the patient and the dentist.5,6

Another study by Eidelman et al showed more than $90 \%$ of the restorations placed under GA were rated as successful based on the marginal adaptation and anatomic form. Parents will be educated about all level of procedures of local and general anaesthesia.

Paediatric patients who are classified generally for the need of GA treatment are those with disability, emotional immaturity and anxiety who need wide range of rehabilitation. As well as a very young age or those are having physical, cognitive, and mental impairment.4,7 Most applicants demanding this kind of treatment are children who have one prevalent health problem such as Early Childhood Caries (ECC).6,7

Patient satisfaction is an important role in determining the utilization of the healthcare services and the compliance behavior of the patients. ${ }^{8}$ In a study done by Vellingiri and Gurunathan ${ }^{8}$ it was found that most of the parents' preference was to localize anaesthesia $(97 \%)$ and preferred general anaesthesia under given circumstances. But there are no enough amount of evidence to assess the parent's preference to GA or LA (Local Anaesthesia) for children undergoing dental treatment among Saudi Arabia. Therefore the aim of the present study was to assess the parents' knowledge and acceptance to treat their children under general anaesthesia in Riyadh city.

\section{METHODS}

The study was approved by the Institutional Review Board (IRB) of the Faculty of Dentistry, REU FUGRP / 2019 / 69 and IRB number RC / IRB / 2019 / 278

This cross-sectional survey was conducted among parents presenting to REU (Riyadh Elm University) in Namuthajiyah Campus for dental treatment, to determine their acceptance to treat their children under general anaesthesia for dental procedures from November 2019 to June 2020. Parents with children older than 14-year-old and less than the age of 3 and having children with mental impairment and cardiac diseases or any other medical or mental problem were excluded. All the parents fulfilling inclusion criteria were explained about the purpose of the study and a total of 452 parents provided informed consent during the aforementioned period were included for the survey.
The survey was carried out using a structured, selfadministered and close ended questionnaire. The first part of questionnaire enquired regarding demographics like age of parents and child, educational status of parents and relationship with child. This was followed by items regarding their perceptions concerning use of GA during dental tretaments like effectiveness of such treatments, worry due to such treatments, impact of these treatments on child's behaviour towards dentists etc. Along with these, reasons for refusal or acceptance of dental procedures under GA were also asked. The time alloted to each patient for filling the questionnaire was approximately 8 - 10 minutes and regional language was used.

A pilot study was carried outbefore the main survey on 25 patients for the validation of the questionnaire. The participants of this pilot survey were not included in main study. The Cronbach's alpha and split-half reliability values for the items of questionnaire were found to be 0.84 and 0.80 , respectively.

\section{Statistical Analysis}

All the data entered into the statistical Software Package for Social Sciences (SPSS-IBM, version 25, Armonk, NY, USA), and analyzed. Descriptive statistics of frequency distribution and percentages calculated for demographic variables and questionnaire items. Chi-squares tests applied to assess the relationship between categorical variables. A p-value of $(\mathrm{p}<$ 0.05 ) was considered significant for all statistical purposes.

\section{RESULTS}

A total of 452 parents (mothers $=290$, fathers $=162$ ) of the children participated in the study. Majority of the parents belonged to the 31 - 40 years of age 169 (37.4\%), having bachelor's degree of educational level 204 (45.1\%). Most of the parents reported to have of $4-8$ years $183(40.5 \%)$ children, as shown in (Table 1).

\begin{tabular}{|c|c|c|c|}
\hline & Variables & $\mathbf{n}$ & $\%$ \\
\hline \multirow{5}{*}{ Age (Years) } & $18-30$ & 151 & $33.4 \%$ \\
\hline & $31-40$ & 169 & $37.4 \%$ \\
\hline & $41-50$ & 88 & $19.5 \%$ \\
\hline & Above 50 & 44 & $9.7 \%$ \\
\hline & Total & 452 & $100.0 \%$ \\
\hline \multirow{5}{*}{ Educational Level } & Lower than high school & 68 & $15.0 \%$ \\
\hline & High school & 153 & $33.8 \%$ \\
\hline & Bachelor's degree & 204 & $45.1 \%$ \\
\hline & Higher than bachelors & 27 & $6.0 \%$ \\
\hline & Total & 452 & $100.0 \%$ \\
\hline \multirow{3}{*}{ Relationship with Child } & Mother & 290 & $64.2 \%$ \\
\hline & Father & 162 & $35.8 \%$ \\
\hline & Total & 452 & $100.0 \%$ \\
\hline \multirow{5}{*}{ Age of the Child (Years) } & $2-4$ & 122 & $27.0 \%$ \\
\hline & $4-8$ & 183 & $40.5 \%$ \\
\hline & $9-12$ & 110 & $24.3 \%$ \\
\hline & More than 12 & 37 & $8.2 \%$ \\
\hline & Total & 452 & $100.0 \%$ \\
\hline \multirow{2}{*}{ Residence } & Riyadh & 426 & $94.2 \%$ \\
\hline & Other & 26 & $5.8 \%$ \\
\hline
\end{tabular}

Most of the parents who participated in the study reported that their children were healthy 416 (92\%), while $30(6.6 \%)$, $2(0.4 \%), 2(0.4 \%)$ and $2(0.4 \%)$ suffered from respiratory, endocrine and gastric problems (Figure 1). 


\begin{tabular}{|c|c|c|c|c|c|c|c|c|c|c|c|c|c|}
\hline & \multirow{3}{*}{ Variables } & \multicolumn{6}{|c|}{ Comprehensive Dental Care for Child under GA } & \multicolumn{6}{|c|}{ Feeling towards GA } \\
\hline & & \multicolumn{2}{|c|}{ Effective } & \multicolumn{2}{|c|}{ Ineffective } & \multicolumn{2}{|c|}{ Effective } & \multicolumn{2}{|c|}{ Ineffective } & \multicolumn{2}{|c|}{ Effective } & \multicolumn{2}{|c|}{ Ineffective } \\
\hline \multirow{7}{*}{$\begin{array}{l}\text { Age of Parent } \\
\text { (Years) }\end{array}$} & & $\mathrm{n}$ & $\%$ & $\mathrm{n}$ & $\%$ & $\mathrm{n}$ & $\%$ & $\mathrm{n}$ & $\%$ & $\mathrm{n}$ & $\%$ & $\mathrm{n}$ & $\%$ \\
\hline & $18-30$ & 50 & $27.6 \%$ & 26 & $33.8 \%$ & 75 & $38.7 \%$ & 82 & $34.9 \%$ & 38 & $30.4 \%$ & 31 & $33.7 \%$ \\
\hline & $31-40$ & 77 & $42.5 \%$ & 27 & $35.1 \%$ & 65 & $33.5 \%$ & 89 & $37.9 \%$ & 51 & $40.8 \%$ & 29 & $31.5 \%$ \\
\hline & $40-50$ & 35 & $19.3 \%$ & 15 & $19.5 \%$ & 38 & $19.6 \%$ & 42 & $17.9 \%$ & 23 & $18.4 \%$ & 23 & $25.0 \%$ \\
\hline & $>50$ & 19 & $10.5 \%$ & 9 & $11.7 \%$ & 16 & $8.2 \%$ & 22 & $9.4 \%$ & 13 & $10.4 \%$ & 9 & $9.8 \%$ \\
\hline & P value & & & 0.37 & & & & & & & 0.722 & & \\
\hline & Lower than High school & 19 & $10.5 \%$ & 18 & $23.4 \%$ & 31 & $16.0 \%$ & 32 & $13.6 \%$ & 23 & $18.4 \%$ & 13 & $14.1 \%$ \\
\hline \multirow{4}{*}{$\begin{array}{l}\text { Educational } \\
\text { Level of Parent }\end{array}$} & High school & 52 & $28.7 \%$ & 29 & $37.7 \%$ & 72 & $37.1 \%$ & 79 & $33.6 \%$ & 45 & $36.0 \%$ & 29 & $31.5 \%$ \\
\hline & Bachelor's degree & 93 & $51.4 \%$ & 30 & $39.0 \%$ & 81 & $41.8 \%$ & 107 & $45.5 \%$ & 56 & $44.8 \%$ & 41 & $44.6 \%$ \\
\hline & Higher than a bachelor's & 17 & $9.4 \%$ & 0 & $0.0 \%$ & 10 & $5.2 \%$ & 17 & $7.2 \%$ & 1 & $0.8 \%$ & 9 & $9.8 \%$ \\
\hline & P value & & & 0.00 & & & & & & & 0.120 & & \\
\hline \multirow{4}{*}{ Relation } & Mother & 114 & $63.0 \%$ & 43 & $55.8 \%$ & 133 & $68.6 \%$ & 149 & $63.4 \%$ & 87 & $69.6 \%$ & 54 & $58.7 \%$ \\
\hline & Father & 67 & $37.0 \%$ & 34 & $44.2 \%$ & 61 & $31.4 \%$ & 86 & $36.6 \%$ & 38 & $30.4 \%$ & 38 & $41.3 \%$ \\
\hline & $P$ value & & & 0.13 & & & & & & & 0.239 & & \\
\hline & $2-4$ & 44 & $24.3 \%$ & 22 & $28.6 \%$ & 56 & $28.9 \%$ & 60 & $25.5 \%$ & 33 & $26.4 \%$ & 29 & $31.5 \%$ \\
\hline \multirow{4}{*}{$\begin{array}{l}\text { Child Age } \\
\text { (Years) }\end{array}$} & $5-8$ & 73 & $40.3 \%$ & 30 & $39.0 \%$ & 80 & $41.2 \%$ & 97 & $41.3 \%$ & 54 & $43.2 \%$ & 32 & $34.8 \%$ \\
\hline & $9-12$ & 52 & $28.7 \%$ & 22 & $28.6 \%$ & 36 & $18.6 \%$ & 56 & $23.8 \%$ & 30 & $24.0 \%$ & 24 & $26.1 \%$ \\
\hline & More than 12 & 12 & $6.6 \%$ & 3 & $3.9 \%$ & 22 & $11.3 \%$ & 22 & $9.4 \%$ & 8 & $6.4 \%$ & 7 & $7.6 \%$ \\
\hline & $P$ value & & & 0.11 & & & & & & & 0.812 & & \\
\hline \multirow{3}{*}{ Residence } & Riyadh & 173 & $95.6 \%$ & 72 & $93.5 \%$ & 181 & $93.3 \%$ & 220 & $93.6 \%$ & 116 & $92.8 \%$ & 90 & $97.8 \%$ \\
\hline & Outside Riyadh & 8 & $4.4 \%$ & 5 & $6.5 \%$ & 13 & $6.7 \%$ & 15 & $6.4 \%$ & 9 & $7.2 \%$ & 2 & $2.2 \%$ \\
\hline & P value & & & 0.60 & & & & & & & 0.243 & & \\
\hline
\end{tabular}

\begin{tabular}{|c|c|c|c|c|}
\hline & \multirow{3}{*}{ Variables } & \multicolumn{3}{|c|}{ Parent Refusal of Treatment under GA } \\
\hline \multirow{5}{*}{ Age of Parent } & & Fear of the child not waking up & Cost & Bad experience \\
\hline & & $\mathrm{N}(\%)$ & $\mathrm{N}(\%)$ & $\mathrm{N}(\%)$ \\
\hline & $18-30$ & $162(35.8)$ & $130(28.7)$ & $107(23.7)$ \\
\hline & $31-40$ & $167(37.0)$ & $156(34.5)$ & $79(17.4)$ \\
\hline & $>50$ & $40(8.9)$ & $47(10.3)$ & $71(15.8)$ \\
\hline \multirow{6}{*}{$\begin{array}{c}\text { Education Level of } \\
\text { Parent }\end{array}$} & $\mathrm{p}$ value & & 0.502 & \\
\hline & Lower than High school & $60(13.3)$ & $78(17.2)$ & $95(21.1)$ \\
\hline & High school & $153(33.9)$ & $177(39.1)$ & $95(21.1)$ \\
\hline & Bachelor s degree & $205(45.3)$ & $192(42.5)$ & $226(50.0)$ \\
\hline & higher than a bachelors & $32(7.0)$ & $5(1.1)$ & $36(7.9)$ \\
\hline & P value & & 0.129 & \\
\hline \multirow{4}{*}{ Relation } & Mother & $301(66.7)$ & $260(57.5)$ & $262(57.9)$ \\
\hline & Father & $151(33.3)$ & $192(42.5)$ & $190(42.1)$ \\
\hline & P value & & 0.192 & \\
\hline & $2-4$ & $124(27.5)$ & $125(27.6)$ & $95(21.1)$ \\
\hline \multirow{4}{*}{ Child Age } & 33 & $195(43.1)$ & $146(32.2)$ & $166(36.8)$ \\
\hline & 941 & $94(20.8)$ & $165(36.6)$ & $119(26.3)$ \\
\hline & More than 12 & $39(8.6)$ & $15(3.4)$ & $71(15.8)$ \\
\hline & P value & & 0.021 & \\
\hline \multirow{2}{*}{ Residence } & Riyadh & $423(93.6)$ & 437 (96.6) & $428(94.7)$ \\
\hline & P value & & 0.620 & \\
\hline & Table 3. Pa & fusal of Dental Treatment & under $G A$ & \\
\hline
\end{tabular}

\begin{tabular}{|c|c|c|c|c|c|c|c|c|c|c|c|c|}
\hline \multirow{3}{*}{\multicolumn{2}{|c|}{ Variables }} & \multicolumn{4}{|c|}{ GA is for a Specific Class } & \multicolumn{4}{|c|}{$\begin{array}{c}\text { GA has an Impact on the Child's Behaviour } \\
\text { towards the Dentist }\end{array}$} & \multicolumn{3}{|c|}{$\begin{array}{l}\text { Decision to Accept Treatment } \\
\text { under GA is Affected }\end{array}$} \\
\hline & & $\begin{array}{l}\text { Special } \\
\text { Needs } \\
\text { Category }\end{array}$ & $\begin{array}{l}\text { Non- } \\
\text { Cooperative } \\
\text { Children }\end{array}$ & $\begin{array}{l}\text { Age Group } 18 \\
\text { Years or Older }\end{array}$ & $\begin{array}{l}\text { Special } \\
\text { Needs } \\
\text { Category }\end{array}$ & $\begin{array}{c}\text { Non- } \\
\text { Cooperative } \\
\text { Children }\end{array}$ & $\begin{array}{l}\text { Age Group } 18 \\
\text { Years or Older }\end{array}$ & $\begin{array}{c}\text { Special } \\
\text { Needs } \\
\text { Category }\end{array}$ & $\begin{array}{c}\text { Non- } \\
\text { Cooperative } \\
\text { Children }\end{array}$ & $\begin{array}{l}\text { Age Group } 18 \\
\text { Years or Older }\end{array}$ & $\begin{array}{l}\text { Special } \\
\text { Needs } \\
\text { Category }\end{array}$ & $\begin{array}{c}\text { Non- } \\
\text { Cooperative } \\
\text { Children }\end{array}$ \\
\hline & & $\mathrm{n} \%$ & $\mathrm{n} \%$ & $\mathrm{n} \%$ & $\mathrm{n} \%$ & $\mathrm{n} \%$ & $\mathrm{n} \%$ & $\mathrm{n} \%$ & $\mathrm{n} \%$ & $\mathrm{n} \%$ & $\mathrm{n} \%$ & $\mathrm{n} \%$ \\
\hline \multirow{5}{*}{$\begin{array}{l}\text { Age of } \\
\text { Parent }\end{array}$} & $18-30$ & $19(27.5 \%)$ & $60(32.4 \%)$ & $24(40.0 \%)$ & $48(34.8 \%)$ & $40(30.1 \%)$ & $7(41.2 \%)$ & $50(30.7 \%)$ & $54(38.8 \%)$ & $82(31.7 \%)$ & $36(31.6 \%)$ & $33(41.8 \%$ \\
\hline & $31-40$ & $28(40.6 \%)$ & $79(42.7 \%)$ & $19(31.7 \%)$ & $43(31.2 \%)$ & $54(40.6 \%)$ & $7(41.2 \%)$ & $63(38.7 \%)$ & $45(32.4 \%)$ & $100(38.6 \%)$ & $38(33.3 \%)$ & $31(39.2 \%)$ \\
\hline & $40-50$ & $14(20.3 \%)$ & $32(17.3 \%)$ & $9(15.0 \%)$ & $33(23.9 \%)$ & $25(18.8 \%)$ & $1(5.9 \%)$ & $31(19.0 \%)$ & $31(22.3 \%)$ & $54(20.8 \%)$ & $22(19.3 \%)$ & $12(15.2 \%)$ \\
\hline & $>50$ & $8(11.6 \%)$ & $14(7.6 \%)$ & & $14(10.1 \%)$ & & $2(11.8 \%)$ & $19(11.7 \%)$ & $9(6.5 \%)$ & & $18(15.8 \%)$ & \\
\hline & $P$ value & \multicolumn{4}{|c|}{.383} & \multicolumn{4}{|c|}{.503} & \multicolumn{3}{|c|}{.087} \\
\hline \multirow{5}{*}{$\begin{array}{c}\text { Educa } \\
\text { tional } \\
\text { level } \\
\text { of } \\
\text { parent }\end{array}$} & $\begin{array}{l}\text { Lower than } \\
\text { High school }\end{array}$ & $10(14.5 \%)$ & $22(11.9 \%)$ & $13(21.7 \%)$ & $23(16.7 \%)$ & $20(15.0 \%)$ & $1(5.9 \%)$ & $22(13.5 \%)$ & $25(18.0 \%)$ & $38(14.7 \%)$ & $21(18.4 \%)$ & $9(11.4 \%)$ \\
\hline & High school & $29(42.0 \%)$ & $47(25.4 \%)$ & $23(38.3 \%)$ & $54(39.1 \%)$ & $35(26.3 \%)$ & $6(35.3 \%)$ & $61(37.4 \%)$ & $51(36.7 \%)$ & $88(34.0 \%)$ & $37(32.5 \%)$ & $28(35.4 \%)$ \\
\hline & $\begin{array}{l}\text { Bachelor's } \\
\text { degree }\end{array}$ & $29(42.0 \%)$ & $100(54.1 \%)$ & $22(36.7 \%)$ & $53(38.4 \%)$ & $66(49.6 \%)$ & $10(58.8 \%)$ & $70(42.9 \%)$ & $58(41.7 \%)$ & $115(44.4 \%)$ & $52(45.6 \%)$ & $37(46.8 \%)$ \\
\hline & $\begin{array}{l}\text { Higher than a } \\
\text { bachelor's }\end{array}$ & $1(1.4 \%)$ & $16(8.6 \%)$ & $2(3.3 \%)$ & $8(5.8 \%)$ & $12(9.0)$ & $0(0.0 \%)$ & $10(6.1 \%)$ & $5(3.6 \%)$ & $18(6.9 \%)$ & $4(3.5 \%)$ & $5(6.3 \%)$ \\
\hline & P value & \multicolumn{4}{|c|}{$0.013^{*}$} & \multicolumn{4}{|c|}{.247} & \multicolumn{3}{|c|}{.758} \\
\hline \multirow{3}{*}{$\begin{array}{c}\text { Relati } \\
\text { on }\end{array}$} & Mother & $44(63.8 \%)$ & 127 (68.6\%) & 41 (68.3\%) & $78(56.5 \%)$ & $82(61.7 \%)$ & $11(64.7 \%)$ & $111(68.1 \%)$ & $86(61.9 \%)$ & & $72(63.2 \%)$ & $47(59.5 \%)$ \\
\hline & Father & & & & $60(43.5 \%)$ & & $6(35.3 \%)$ & & $53(38.1 \%)$ & & $42(36.8 \%)$ & \\
\hline & $P$ value & \multicolumn{4}{|c|}{.134} & \multicolumn{4}{|c|}{.619} & \multicolumn{3}{|c|}{.552} \\
\hline \multirow{6}{*}{$\begin{array}{l}\text { Child } \\
\text { age }\end{array}$} & $2-4$ & $20(29.0 \%)$ & $50(27.0 \%)$ & $12(20.0 \%)$ & $40(29.0 \%)$ & $41(30.8 \%)$ & $5(29.4 \%)$ & $38(23$ & $38(27.3 \%)$ & $67(25.9 \%)$ & $28(24.6 \%)$ & \\
\hline & $5-8$ & $26(37.7 \%)$ & $80(43.2 \%)$ & $.7 \%)$ & $52(37.7 \%)$ & $52(39.1 \%)$ & $7(41.2 \%)$ & $64(39.3 \%)$ & & $8 \%)$ & $47(41.2$ & \\
\hline & $9-12$ & $21(30.4 \%)$ & $39(21.1 \%)$ & $16(26.7 \%)$ & $34(24.6 \%)$ & $31(23.3 \%)$ & $4(23.5 \%)$ & $48(29.4 \%)$ & $27(19.4 \%)$ & $65(25.1 \%)$ & $31(27.2 \%)$ & $14(17.7 \%)$ \\
\hline & More than 12 & $2(2.9 \%)$ & $16(8.6 \%)$ & 7 (11.7 \%) & $12(8.7 \%)$ & $9(6.8 \%)$ & $1(5.9 \%)$ & $13(8.0 \%)$ & $14(10.1 \%)$ & $24(9.3 \%)$ & $8(7.0 \%)$ & $5(6.3 \%)$ \\
\hline & P value & \multicolumn{4}{|c|}{.585} & \multicolumn{4}{|c|}{.720} & \multicolumn{3}{|c|}{.580} \\
\hline & Riyadh & $69(100 \%)$ & $174(94.1 \%)$ & 58 (96.7 \%) & $125(90.6 \%)$ & $130(97.7 \%)$ & $15(88.2 \%)$ & $154(94.5 \%)$ & $127(91.4 \%)$ & $244(94.2 \%)$ & $107(93.9 \%)$ & $75(94.9 \%)$ \\
\hline \multirow[t]{2}{*}{$\begin{array}{c}\text { Reside } \\
\text { nce }\end{array}$} & $\begin{array}{l}\text { Outside } \\
\text { Riyadh }\end{array}$ & $0(0.0 \%)$ & $11(5.9 \%)$ & $2(3.3 \%)$ & $13(9.4 \%)$ & $3(2.3 \%)$ & $2(11.8 \%)$ & $9(5.5 \%)$ & $12(8.6 \%)$ & $15(5.8 \%)$ & $7(6.1 \%)$ & $4(5.1 \%)$ \\
\hline & $\mathrm{p}$ & \multicolumn{4}{|c|}{0.008} & \multicolumn{4}{|c|}{0.085} & \multicolumn{3}{|c|}{0.949} \\
\hline \multicolumn{13}{|c|}{ Table 4. GA Indications, Impact and Decision to Accept Treatment under GA } \\
\hline
\end{tabular}


Amongst all the sociodemographic variables, educational level of the parents was found to be significantly associated with the effectiveness of the comprehensive dental care for their child under GA ( $\mathrm{p}=0.003^{*}$ ). While other sociodemographic variables did not show any significant association with the effectiveness of the comprehensive dental care for the child under GA (Table 2).

Child age showed significant association with the parental refusal of dental treatment under GA $(p=0.021)$. (Table 3$)$. Educational level of the parents and residence were found to be significantly associated with the perception that the dental treatment under GA is indicated for a specific class of patients $(p=0.013)$ and $(p=0.008)$ (Table 4).

\section{DISCUSSION}

Findings in this study show that majority of the educated parents have agreed that GA is effective in improving the quality of life \& childs' health $\left(p=0.003^{*}\right)$. Findings of a previous study reveals that, parents believed that the overall health of their child had improved as a result of comprehensive dental intervention. (82\%) ${ }^{9}$ In the study of Mavridou $\mathrm{P}^{10}$ they reported the major causes of patients' fears for GA is not waking up after surgery (56.4 \%), but in present study only (37 \%) of participants answered fears of not waking up, which give us clue that there are other reasons that affect in the decision to accept treatment under GA.

The time required for completion of dental rehabilitation is considerably fluctuating Because of operation complexity, estimating operation time is not exact most of operations may take longer or shorter duration than estimated preoperatively, the significant value was variable among socio-demographic (age, educational level of parents ) $(p=0.005),(p=0.000)$ and $(\mathrm{p}=0.003)$, Likewise, Forsyth $\mathrm{AR}$ et $\mathrm{al}^{3}$ found that the time of procedure ranged from $15 \mathrm{~min}$ to $120 \mathrm{~min}$ also may be increased according to type of procedure associated with: patient age $(p=0.01)$; ASA classification $(p=0.006)$; treatment type $(\mathrm{p}<0.001)$; number of teeth treated $(\mathrm{p}<0.001)$; and dentist operator type $(\mathrm{p}=0.005)$.

Educational level of the parents and residence were found to be significantly associated with the perception that the dental treatment under GA is indicated for a specific class of patients $(p=0.013)$ and $(p=0.008)$ (Table 4).

Similarly in another study authors agreed that in clinical relevance, patients with severe disablement, dental GA presents the only treatment option, specific preventive programs should be implemented for patients with minor disablement or dentist phobia. ${ }^{11}$ From this study the tooth brushing frequency in children was one time a day (313) $(69.2$ $\%)$. Likewise Soltani R et al,12 found that children's brushing frequency twice a day was $12.8 \%$ and once a day $43.7 \%$ ( $<$ 0.05 )

\section{Limitations}

Some parents refused to participate. So, the data collected might not be big and moreover the study was done in just one institute (REU Namuthajiyah Campus); so, generalizability of the results has to be seen with caution.

\section{CONCLUSIONS}

From this study, we conclude that the education level will affect the parent's knowlage and awareness with regard to treat their children under GA. We observed in this study, insuffient awareness of parents toward regular dental check up. It is important to educate parents about oral health and diseases to become aware about prevention rather than intervetion.

Data sharing statement provided by the authors is available with the full text of this article at jemds.com.

Financial or other competing interests: None.

Disclosure forms provided by the authors are available with the full text of this article at jemds.com.

The authors would like to thank all participants for their agreement and participation.

Haneen Al Shukairy made the concept of the study and review of literature, Bayan Alsahwan also made the concept of the study and final manuscript writing, Massoma Alkhabbaz assisted in questionnaire preparation and data collection, Maryam Alkhwajah did data collection and data entry, Zainab Bumajdad also assisted in data analysis and manuscript writing and Zahra Alradwan wrote overall final manuscript checking and preparation.

All procedures performed in studies involving human participants were in accordance with the ethical standards of the Institutional and / or National Research Committee and with the 1964 Helsinki declaration and its later amendments or comparable ethical standards (ethical approval number REU FUGRP / 2019 / 69 and IRB number RC / IRB / 2019 / 278).

\section{REFERENCES}

[1] Foster H, Fitzgerald J. Dental disease in children with chronic illness. Arch Dis Child 2005;90(7):703-8.

[2] Chandrapooja J, Selvarasu K. Behavioural management techniques inpaediatric clinic. Int J Pharm Biol Sci 2016;6(3):10-5.

[3] Forsyth AR, Seminario AL, Scott J, et al. General anaesthesia time for Paediatric dental cases. Pediatr Dent 2012;34(5):129-35.

[4] Adewale L. Anaesthesia for paediatric dentistry. Continuing Education in Anaesthesia Critical Care \& Pain 2012;12(6):288-94.

[5] Lee JY, Roberts MW. Mortality risks associated with Paediatric dental care using general anaesthesia in a hospital setting. J Clin Pediatr Dent 2003;27(4):381-3.

[6] Atan S, Ashley P, Gilthorpe MS, et al. Morbidity following dental treatment of children under intubation general anaesthesia in a day- stay unit. Int J Pediatr Dent 2004;14(1):9-16.

[7] Filstrup SL, Briskie D, da Fonseca M, et al. Early childhood caries and quality of life: child and parent perspectives. Pediatr Dent 2003;25(5):431-40.

[8] Vellingiri S, Gurunathan D. Assessment of parent's preference to general or local anaesthesia for children undergoing dental treatment. World J Dent 2015;6(3):154-60.

[9] Acs G, Pretzer S, Foley M, et al. Perceived outcomes and parental satisfaction following dental rehabilitation under general anaesthesia. Pediatr Dent 2001;23(5):41923. 
[10] Mavridou P, Dimitriou V, Manataki A, et al. Patient's anxiety and fear of anaesthesia: effect of gender, age, education and previous experience of anaesthesia. A survey of 400 patients. J Anaesth 2013;27(1):104-8.

[11] Schnabl D, Guarda A, Guarda M, et al. Dental treatment under general anaesthesia in adults with special needs at the University Hospital of Dental Prosthetics and
Restorative Dentistry of Innsbruck, Austria: a retrospective study of 12 years. Clin Oral Investig 2019;23(11):4157-62.

[12] Soltani R, Eslami AA, Akhlaghi N, et al. Toothbrushing frequency among 4-6-year-old Iranian children and associated maternal attitude and sociobehavioral factors. Dent Res J (Isfahan) 2017;14(1):50-6. 